\title{
Teoria das Situações Didáticas e seus elementos para o ensino de Física e Matemática
}

\author{
Ferreira, M. V. V.1*; Ferreira, A.T ${ }^{2}$; Souza, M.A.V. F ${ }^{1}$; \\ 1 Programa de Pós-Graduação em Educação Ciências e Matemática, Instituto Federal do Espírito Santo, Vitória, ES, Brasil. \\ 2 Faculdade do Centro Leste, Vitória,ES,Brasil. \\ * e-mail: marcusvvft@gmail.com
}

\begin{abstract}
Resumo
O presente artigo busca apresentar a Teoria das Situações Didáticas surgida no contexto do período matemática moderna, período que foi marcado por diversas mudanças na forma de ensino de matemática e apresentar elementos dessa teoria que podem contribuir para o ensino de Física e Matemática.
\end{abstract}

\begin{abstract}
This article seeks to present the Theory of Didactic Situations arising in the context of modern mathematics period, a period that was marked by several changes in the form of mathematics teaching and presenting elements of theory that can contribute to the teaching of physics and mathematics

Keywords (Palavras chaves): Didactic Situations, teaching
\end{abstract}

\section{Introdução}

A Teoria das Situações Didáticas teve seu inicio através dos estudos desenvolvidos no Instituto de Investigação do Ensino de Matemática (IREM), no final da década de 1960, num período conhecido como movimento da Matemática moderna. Inicialmente 0 campo de atuação do IREM era a formação continuada de professores de matemática e produção de novos objetos de aprendizagem, como jogos, problemas, experimentos de ensino, dentre outros meios desenvolvidos para potencializar a produção de materiais para sala de aula.

Guy Brousseau, professor e pesquisador do IREM da área da Educação Matemática, desenvolveu uma estrutura de ensino e aprendizagem, verificando e valorizando cada etapa deste processo de construção de conhecimento matemático, conceituando assim a chamada Teoria das Situações Didáticas (TSD).
Pommer (2008) em seu artigo 'Brousseau e a idéia de Situação Didática', destaca um dos grupos de pesquisas do IREM como o formado pelos pesquisadores Yves Chevallard, Régine Douady, Raymond Duval, Gérard Vergnaud pelos trabalhos desenvolvidos e dentre os trabalhos apresentados encontra-se a Teoria das Situações desenvolvida por Guy Brousseau.

\section{Biografia de Guy Brousseau}

Guy Brousseau (1986), um dos primeiros pesquisadores da Didática Matemática Francesa, juntamente com seu grupo de estudos, desenvolveu uma teoria denominada de teoria das situações didáticas (TSD). A TSD representa um avanço no ensino e aprendizado da matemática. Entre tantas outras teorias surgidas dos anos 70 para cá, ela adquiriu o caráter de instrumento científico ao associar 
as contribuições de outras disciplinas, propiciando o aperfeiçoamento do ensino de matemática.

Brousseau em 1953, começou a lecionar na região de Lot et Garonne. Casou-se com Nadine Labeque, que se tornou sua parceira de trabalho. Nos fins da década de 1960, antes de se formar em Matemática, lecionou na Universidade de Bordeaux. Atualmente, exerce na universidade a função de diretor do Laboratório de Didática das Ciências e das Tecnologias. Em 1991, tornou-se docente do Instituto Normal superior local. Recebeu o título de doutor honoris causa das universidades de Montreal, Genebra e Córdoba. Brousseau é atualmente considerado um dos maiores pesquisadores em todo o mundo da área da didática da matemática, a ponto de ter sido premiado em $2003 \mathrm{com}$ a primeira Medalha Félix Klein.

\section{Elementos da Teoria das Situações Didáticas}

As situações de aprendizagem de Brousseau (1986) têm aporte teórico em Piaget, nos aspectos de adaptação (assimilação e acomodação), por entenderem ser a aprendizagem uma ação endógena, ou seja, de dentro para fora. Os elementos da teoria de Brousseau buscam contribuir para o processo investigativo, e podem contribuir para aulas alternativas de Física e Matemática.

A proposta de Brousseau (1986) com as TSD prega:

- A observação da aprendizagem em cada etapa do processo de produção do conhecimento matemático;

- As estruturas lógicas de desenvolvimento e as diversas formas de produções dos alunos nas aulas;

- Que cada conhecimento pode ser determinado por uma situação, com participação e relação entre o aluno, professor, saber e o meio.

Uma situação didática segundo Brousseau é uma relação entre o aluno, o professor e conhecimento, planejada pelo docente para que todos os envolvidos se apropriem, de maneira a produzir significado, ou seja, é uma simulação do trabalho de um pesquisador que cria instrumentos para resolver um problema. Brousseau (2008) ressalta que em uma situação escolar, o professor organiza e constitui um meio, que pode ser, por exemplo, um problema, que revela mais ou menos claramente sua intenção de ensinar ao aluno em saber determinado, mas dissimula suficientemente esse saber e a resposta esperada para que o aluno os possa encontrar sozinho, por meio de uma adaptação pessoal ao problema formulado.

Para modelagem das situações didáticas, Brousseau (2008) propõe quatro etapas, que são: devolução, ação, formulação, validação e institucionalização.

- Na etapa de devolução os alunos aceitam participar do processo de aprendizagem. Nessa etapa, o aluno torna-se responsável por parte da aprendizagem, antes condicionada somente na figura do professor.

- Na etapa de ação, o aluno perante a situação didática interage com a aula e cria procedimentos, planeja resoluções de problemas e formula hipóteses.

- Na formulação, há troca de conhecimentos entre os alunos. Nessa etapa, os alunos procuram modificar a linguagem matemática e contextualizá-la para atender seus objetivos que antes foram planejados.

- No processo de validação tudo que foi estudado é organizado e verificado pelos alunos se as informações obtidas condizem com o esperado, ou seja, é verificado o novo conhecimento que foi construído.

- Por fim, na institucionalização o professor e alunos validam o conhecimento. Nessa etapa, as intenções do professor perante a situação didática é revelada.

Em toda estrutura de aprendizagem Brousseau propõe que ha uma relação entre cada etapa, elas não são processos isolados, e sim cíclicos, ou seja, o aluno atinge níveis de aprendizagem durante a situação didática. Em sua teoria Brousseau (2008) também descreve sobre os tipos de contratos didáticos em sua 
teoria, que regula as relações e objetivos implícitos do professor perante a situação didática, nele contendo as responsabilidades de cada participante, as formas de avaliação e os compromissos implícitos ou não do aluno em relação ao professor e o conhecimento.

Almouloud (2007) comenta que o contrato didático não é composto apenas por regras de convívio ou lista de combinados, mas também, como um contrato pedagógico. O contrato didático seria referente ao processo de ensino e de aprendizagem, geralmente não escrito, mas formado por relações que o professor espera do aluno e das atitudes que o aluno espera do professor, de um modo geral, o que é explicitado em contrato didático são questões sobre avaliações e como as atividades serão feitas.

\section{Aplicação da Teoria das Situações Didáticas no ensino de Física}

Azevedo (2008) em sua dissertação faz uma análise de uma sequência didática de física com o aporte teórico na teoria de Brousseau, o trabalho foi realizado em dois cursos do ensino médio com o delineamento no conteúdo de dualidade onda-partícula. A pesquisa foi realizada com a intenção de atualização do currículo básico de ensino de física e em verificar as relações entre professor-aluno-saber, assim como é delineado na teoria de Brousseau, a proposta objetivou em verificar a situação didática e a sucessão dos contratos didáticos dialogando com a produção de conhecimento do aluno.

Marques e Gobara (2008) descrevem e analisam a teoria de Brousseau em procedimentos de aprendizagem sobre a propagação de ondas sonoras. A metodologia adotada foi a Engenharia Didática, sua pergunta de pesquisa foi: $O$ uso de telefone como artefato tecnológico e seus princípios podem facilitar a aprendizagem de ondas sonoras? Para responder esta pergunta os autores construíram uma sequencia didática na forma de situação-problema. O resultado da investigação mostrou plenamente satisfatório segundo autores, pois os alunos se motivaram com a atividade, tomando a responsabilidade de resolvê-la para si, atitude fundamental na proposta de Guy Brousseau.

\section{Considerações}

Compreender o contexto do surgimento da Teoria das Situações Didáticas é vivenciar e construir conhecimento científico e matemático necessário para um pensamento crítico. A contribuição da teoria de Brousseau nas práticas de ensino nas salas de aula, principalmente nas aulas Física e Matemática são notável, a teoria de Brousseau veio a mudar e quebrar paradigmas existentes no ensino tradicional, o aluno passou a ter um papel ativo durante as aulas e não apena um mero espectador, passando assim a ser também responsável pelo seu aprendizado.

\section{Agradecimentos}

Os autores agradecem ao Grupo de Física Aplicada pela oportunidade.

\section{Referências}

[1] POMMER, W. A. Brousseau e a ideia de Situação Didática. São Paulo: FEUSP, 2008.

[2] BROUSSEAU, G. Introdução a teorias das Situações Didáticas: conteúdos e métodos de ensino. São Paulo: Ática, 2008.

[3] ALMOULOUD, S. A. A Teoria das Situações Didáticas. São Paulo: PUC-SP, 2007.

[4] AZEVEdo, M. C. P. S de. Situações de ensinoaprendizagem: análise de uma sequência didática de física a partir da teoria das situações de Brousseau/Maria Cristina Paternostro Stella de Azevedo; orientação Maurício Pietrocola.São Paulo: s.n,2008.

[5] GOBARA, S.T, MARQUES, S.M. Análise de uma situação adidática visando a aprendizagem de ondas sonoras. Mato Grosso do Sul: UFMS, 2008. 